\title{
Comparison of polymerase chain reaction and Warthin- Starry techniques to detect Leptospira spp. in kidneys of slaughtered cattle
}

\author{
Authors: \\ Shahrzad Azizi ${ }^{1}$ \\ Reza Kheirandish ${ }^{1}$ \\ Elham Rahimi ${ }^{2}$ \\ Affiliations: \\ ${ }^{1}$ Department of Pathology, \\ Shahid Bahonar University of \\ Kerman, Iran \\ ${ }^{2}$ Faculty of Veterinary \\ Medicine, Shahid Bahonar \\ University of Kerman, Iran

\section{Correspondence to:} \\ Shahrzad Azizi \\ Email: \\ azizi.shahrzad@gmail.com \\ Postal address: \\ PO Box 761691411, Kerman \\ 761, Iran
}

Dates:

Received: 03 June 2014 Accepted: 18 Aug. 2014 Published: 12 Nov. 2014

How to cite this article: Azizi, S., Kheirandish, R. \& Rahimi, E., 2014, 'Comparison of polymerase chain reaction and WarthinStarry techniques to detect Leptospira spp. in kidneys of slaughtered cattle', Onderstepoort Journal of Veterinary Research 81(1), Art. \#821, 6 pages. http:// dx.doi.org/10.4102/ojvr v81i1.821

Copyright:

(C) 2014. The Authors.

Licensee: AOSIS

OpenJournals. This work

is licensed under the

Creative Commons

Attribution License.

Read online:
Leptospirosis is a worldwide zoonotic disease that is caused by Gram-negative spirochaetes, Leptospira species. Affected animals excrete the organism in the urine into the environment and act as a source of infection. Cattle are maintenance hosts for some serovars of leptospirosis and are important in the transmission of the infection to humans. At post mortem examination, affected cattle show white spots in their kidneys but these are not specific for leptospirosis. Sometimes it is necessary that leptospirosis be diagnosed in the carcass. Different direct methods, including polymerase chain reaction (PCR), Warthin-Starry silver stain (WS), immunofluorescence (IF) and immunohistochemistry (IHC) can be used in order to diagnose leptospirosis in the affected tissues, such as kidney. The main advantage of the WS technique is direct visualisation of the bacteria in the tissue samples. Silver staining is useful for retrospective studies on formalin-fixed and paraffin-embedded samples but little information is available on the sensitivity and specificity of the technique. The present study aimed to find a simple and inexpensive method that can be used in any laboratory and that also, if clinical samples are not available, can detect Leptospira in tissue samples post mortem. This study was performed on 19 paraffin-embedded kidneys of slaughtered cows that grossly had focal to multifocal white spots. Leptospirosis was confirmed in these samples with PCR based on the LipL32 gene. Out of 19 PCR positive kidneys, Leptospira was identified in 13 stained samples by WS. The kidneys revealed different grades of interstitial nephritis. No relationship was found between severity of lesions and presence of leptospires in the kidneys. The PCR results on the urine and blood were consistent with matching WS stained kidneys. Out of 13 kidneys that were positive with silver staining, 7 matching blood and 10 matching urine samples were confirmed positive for leptospirosis with PCR. In this study, the WS technique provided fewer positive results than PCR. This may be as a result of a low burden of Leptospira in the kidney, but the sensitivity of WS staining needs more investigation.

\section{Introduction}

Leptospirosis is a zoonotic disease occurring in domestic and wild animals worldwide that is caused by Gram-negative spirochaetes of the genus Leptospira (Adler \& De la Peña-Moctezuma 2010; Hazıroğlu \& Milli 2001). This disease is significant for public health. In livestock, leptospirosis leads to septicaemia, hepatitis, nephritis, mastitis, decreased production of meat and milk, abortion and stillbirth (Hazıroğlu \& Milli 2001). Leptospires enter through cuts or abrasions of the skin and mucus membranes such as the conjunctiva and urogenital system (Lilenbaum et al. 2008; Monahan, Callanan \& Nally 2009). The leptospiraemic phase lasts for approximately 10 days until the specific immunoglobulins appear in the blood (Adler \& De la Peña-Moctezuma 2010). After the immune response, leptospires localise in the kidneys of animal hosts (Monahan et al. 2009; Scanziani, Sironi \& Mandelli 1989; Yang, Wu \& Pan 2001) and contaminate the environment by excretion in the urine and act as a source of infection (Bharti et al. 2003; Faine et al. 1999).

Cattle are maintenance hosts for some serovars of Leptospira and may transmit infection to humans (Levett 2001). In necropsy, focal to multifocal white spots are seen in the kidney, but these lesions are not pathognomonic for leptospirosis. Access to a proper diagnostic test in clinical cases or after death is essential for treatment and prevention of leptospirosis. Diagnostic techniques should be easy to use, available and inexpensive, with high specificity and sensitivity. The routine and reference test for leptospirosis is the microscopic agglutination test (MAT) but this technique is expensive and needs a specialised laboratory and living Leptospira serovars (Céspedes et al. 2007; Hernández-Rodríguez et al. 2011). Molecular techniques have many advantages (Levett 2001). Polymerase chain reaction (PCR) is a rapid, sensitive, inexpensive assay and can identify low doses of bacteria (Céspedes et al. 2007). This technique is useful for identification of fastidious and slow-growing organisms, and can be used easily 
even in non-specialised laboratories in comparison to MAT (Céspedes et al. 2007; Hernández- Rodríguez et al. 2011). The presence of Leptospira in the tissue can be detected by direct methods including culture, special staining of tissue and immunohistochemistry (IHC) (Ellis et al. 1983; Thiermann 1977). Microbiological culture is expensive and time consuming and may take more than 8 weeks for results (Obregón et al. 2004; Rahim, Gorbanpour \& Haidari 2005). For IHC, special antibodies need to be provided. Warthin-Starry (WS) silver staining is used for detection of spirochaetes and other bacteria in tissues and smears. It is a simple method and may be performed in any laboratory, but information on detection of leptospires in tissue by silver impregnation is scarce (Fornazari et al. 2012; OrtegaPacheco et al. 2008). In this study, paraffin-embedded kidneys were used for WS staining. All kidneys grossly had white spots on their surfaces and leptospirosis was confirmed by PCR. The agreement between PCR and WS was evaluated in this study.

\section{Materials and methods}

\section{Sample collection}

This retrospective study was performed on 19 paraffinembedded kidneys of slaughtered cattle. These kidneys macroscopically had focal to multifocal white spots on their surfaces and leptospirosis was confirmed with PCR based on the LipL32 gene in a previous study (Azizi et al. 2012). In addition, data on serum and urine of these samples examined by PCR for leptospirosis are available.

\section{Polymerase chain reaction procedure}

Deoxyribonucleic acid (DNA) was extracted from frozen kidneys, buffy coat and urine samples with a high-yield DNA purification kit (Cinnagen Inc., PN811SC, Iran), according to the manufacturer's instructions. Polymerase chain reaction based on the LipL32 gene was performed using the primers 5'ATCTCCGTTGCACTCTTTGC3' and 5'ACCATCATCATCATCGTCCA3' as previously described by Tansuphasiri et al. (2006) to distinguish between pathogenic and saprophytic Leptospira species (also see Azizi et al. 2012). Polymerase chain reaction amplification was performed using the following programme: an initial cycle of denaturation at $94{ }^{\circ} \mathrm{C}$ for $3 \mathrm{~min}, 30$ cycles of denaturation at $94{ }^{\circ} \mathrm{C}$ for $1 \mathrm{~min}$, annealing at $60{ }^{\circ} \mathrm{C}$ for $90 \mathrm{~s}$, extension at $72{ }^{\circ} \mathrm{C}$ for $20 \mathrm{~min}$, a final extension at $72{ }^{\circ} \mathrm{C}$ for $10 \mathrm{~min}$ and holding at $4{ }^{\circ} \mathrm{C}$. The amplified products were analysed by electrophoresis on ethidium bromide-stained 2\% agarose gels and the results were observed using ultraviolet (UV) light. A sample was considered positive when the $474 \mathrm{bp}$ DNA band was obtained (Vital-Brazil et al. 2010; also see Azizi et al. 2012).

\section{Microscopic investigations}

Paraffin-embedded kidneys were sectioned at $5 \mu \mathrm{m}$ thickness, stained with haematoxylin-eosin (HE) and WS silver and examined for interstitial nephritis. Interstitial nephritis was graded according to degree of inflammation as follows: (-) negative; (+) mild, < 4 foci; (++) moderate, 4-6 foci and $(+++)$ severe, $>6$ foci in each section (Rossetti et al. 2004).

\section{Haematoxylin-eosin staining}

For HE staining, the slides were deparaffinised in two jars containing xylene (10 min per step) and then hydrated with distilled water. The nucleus was stained with haematoxylin for $5 \mathrm{~min}$, after which the slides were rinsed in running tap water for $7 \mathrm{~min}$ to remove the haematoxylin. Then eosin was applied for $1 \mathrm{~min}$. Finally, the slides were dehydrated in graded alcohol, cleared in xylene and mounted.

\section{Warthin-Starry staining method}

The sections of PCR positive kidney were deparaffinised, rehydrated with triple-distilled water, and immersed in $1 \%$ silver nitrate solution at $43{ }^{\circ} \mathrm{C}$ for $30 \mathrm{~min}$. Developer solution was prepared during this time. The slides were flooded in developer solution until they became light brown to yellow and then washed rapidly in hot tap water $\left(56^{\circ} \mathrm{C}\right)$. After that the slides were rinsed in distilled water and then dehydrated, cleared in xylene and mounted (Luna 1968). Investigation of tissue sections was carried out using an optical microscope with a magnification of $\times 1000$. In addition, five kidneys that were negative for leptospirosis on PCR were used as negative control.

\section{Statistical analysis}

The association between the results of silver impregnation and PCR data for urine and blood was determined by the Kappa test (K) (Thrusfield 2005). In this statistical test, complete agreement between data corresponds to $\mathrm{K}=1$, and lack of agreement corresponds to $\mathrm{K}=0$.

\section{Results}

\section{Gross and histopathological findings}

Grossly, focal to multifocal white spots, $1 \mathrm{~mm}-5 \mathrm{~mm}$ in

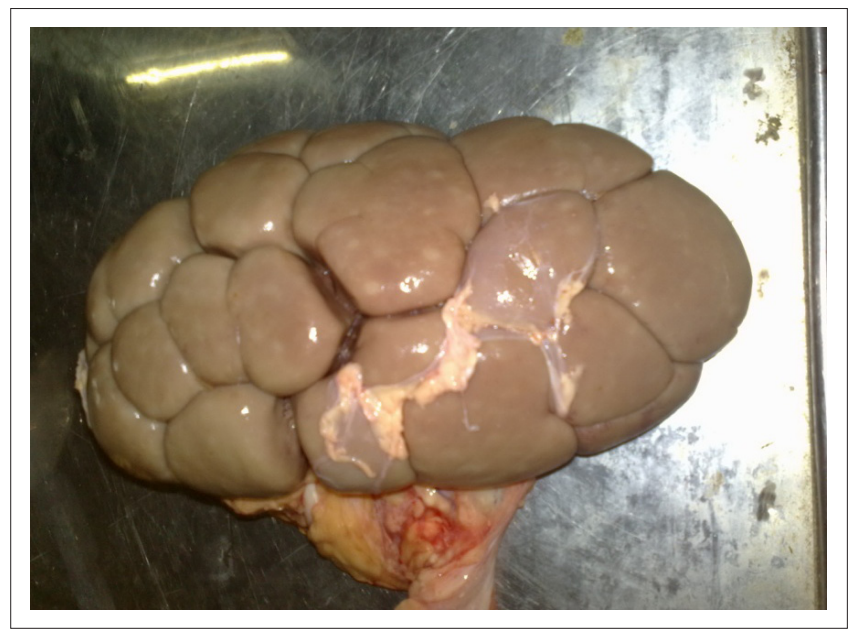

Source: Taken by optika B353 PL, Digital Pro 3, Italy

FIGURE 1: Numerous white spots related to leptospirosis distributed on the surface of a bovine kidney. 
diameter, were randomly distributed on the surface of the kidneys (Figure 1). Histopathological examination revealed mononuclear cells, especially lymphocytes and a few plasma cells, aggregated focally in the interstitial tissues (Figure 2). The lesions were confined to the renal cortex. Mononuclear cells were also infiltrated around the glomeruli and blood vessels. The degree of focal interstitial nephritis in 19 kidneys included 11 samples with mild lesions $(+)$, five with moderate $(++)$ and three with severe lesions $(+++)$.

\section{Warthin-Starry detection}

Leptospira was identified in 13 (68.4\%) out of 19 PCR positive kidneys by WS. Urine $(n=11 / 19)$ and blood $(n=7 / 19)$ samples matching these kidneys were PCR positive in our previous study (Azizi et al. 2012). Leptospira was detected by silver staining in all seven kidneys with matching PCR positive blood samples. Out of 13 WS positive kidneys, 11 matching urine samples had been positive with PCR. Organisms were detected by WS in two kidneys of which the matching urine samples were negative with PCR (Table 1). No relationship was established between degree of histopathological lesions and the presence of the organism. Spirochaetes were observed as spiral or filiform on the apical surface of epithelial cells (Figure 3) and in the lumens of cortical tubules (Figure 4). Low numbers of Leptospira, from one to a maximum of five organisms, were found more frequently in the tubules of the superficial than the deep cortex, and none in the medullary region. The results of WS staining and PCR had moderate agreement with Kappa $(0.55, p<0.01)$ for urine and $(0.42, p>0.02)$ for blood respectively.

\section{Discussion}

Leptospirosis is a spirochaetal infection that threatens both animal and human health. Humans can be affected during occupational activities and contact with infected animals, for example meat inspectors and abattoir staff (Orrego et al. 2003).

Abattoir studies offer an opportunity for tissue sampling and diagnosis of diseases. Cattle act as maintenance hosts for leptospirosis (Levett 2001). Affected cattle may show multiple macroscopic white foci in the renal parenchyma, referred to as 'white-spotted kidney' (Baker et al. 1989; Hunter et al. 1987; Jones et al. 1987). Microscopically, these spots reveal interstitial nephritis, which is a common finding in leptospirosis but not pathognomonic for this disease and may occur with other pathogens. Different technical approaches including PCR, WS, immunofluorescence (IF) and IHC can be used in order to perform diagnosis of leptospirosis in the suspected tissues, such as kidneys (Ahmad, Shah \& Ahmad 2005). The main advantage of WS and IF techniques is direct visualisation of the bacteria in the tissue samples. Silver staining is useful for retrospective studies on formalin-fixed and paraffinembedded samples, but little information is available on the sensitivity and specificity of the test (Szeredi \& Haake 2006).
TABLE 1: Comparative results of polymerase chain reaction and Warthin-Starry staining for detection of Leptospira in tissue samples.

\begin{tabular}{llll}
\hline Number & PCR positive urine & WS positive kidney & PCR positive kidney \\
\hline 1 & - & - & + \\
2 & - & - & + \\
3 & - & - & + \\
4 & - & + & + \\
5 & + & + & + \\
6 & - & + & + \\
7 & - & - & + \\
8 & + & + & + \\
9 & - & - & + \\
10 & + & + & + \\
11 & + & - & + \\
12 & + & + & + \\
13 & + & + & + \\
14 & + & + & + \\
15 & + & + & + \\
16 & + & + & + \\
17 & + & + & + \\
18 & + & + & + \\
19 & - & + & + \\
\hline
\end{tabular}

PCR, Polymerase chain reaction; WS, Warthin-Starry.

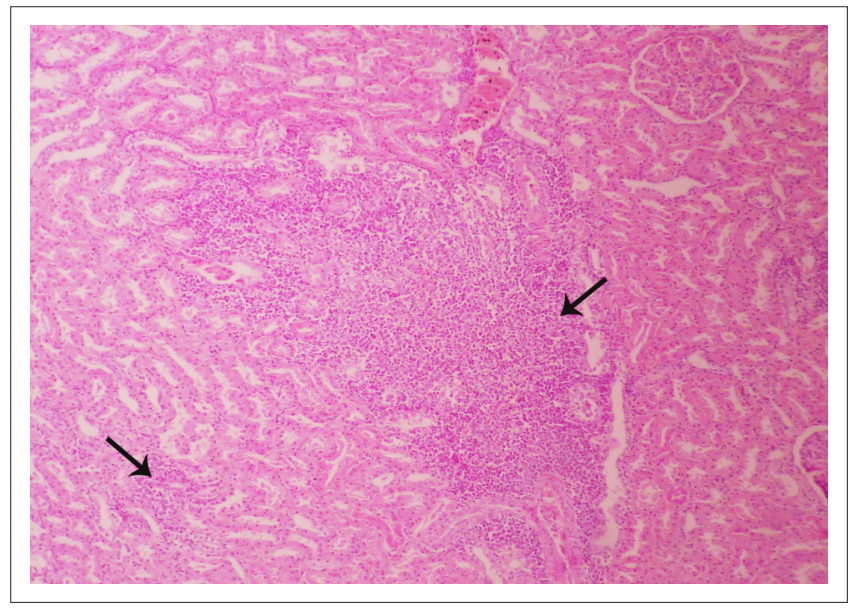

Source: Taken by optika B353 PL, Digital Pro 3, Italy haematoxylin-eosin, $\times 100$.

FIGURE 2: Severe infiltration of mononuclear cells (arrows) in the interstitial tissues of the renal cortex.

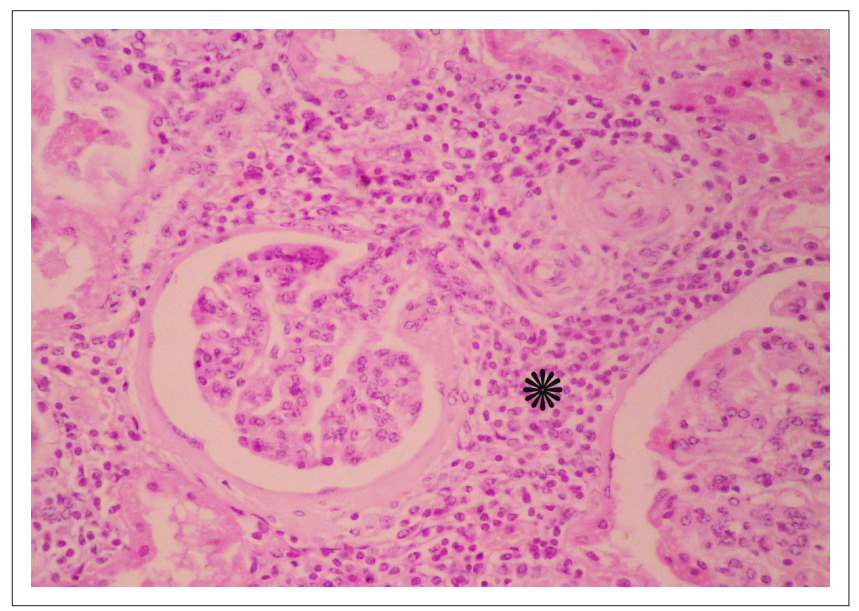

Source: Taken by optika B353 PL, Digital Pro 3, Italy haematoxylin-eosin, $\times 400$.

FIGURE 3: Accumulation of inflammatory mononuclear cells around the glomeruli (asterisk). 


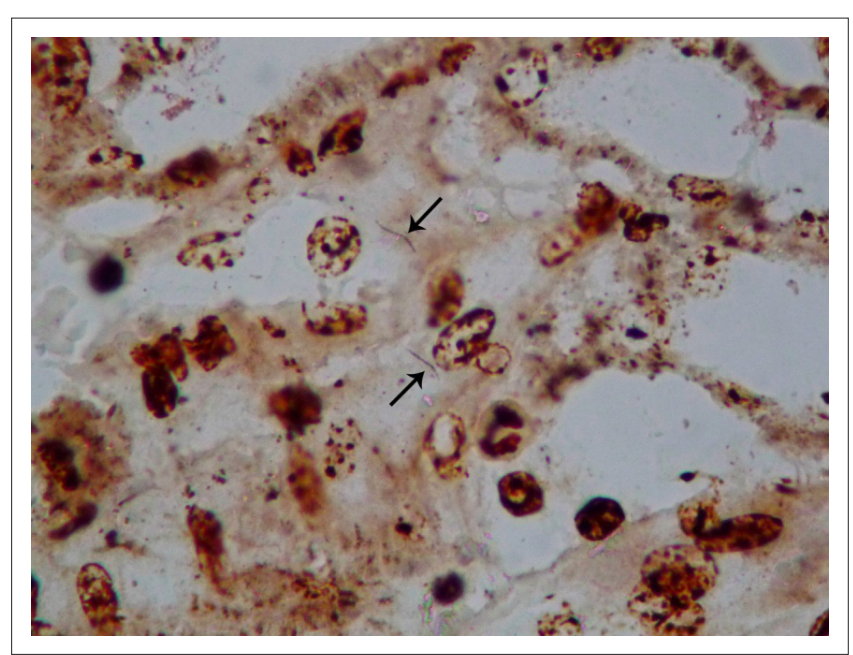

Source: Taken by optika B353 PL, Digital Pro 3, Italy

$\times 1000$.

FIGURE 4: Warthin-Starry staining of kidney. Presence of filiform, dark brown Leptospira (arrows) on the apical surface of epithelial cells in the cortex.

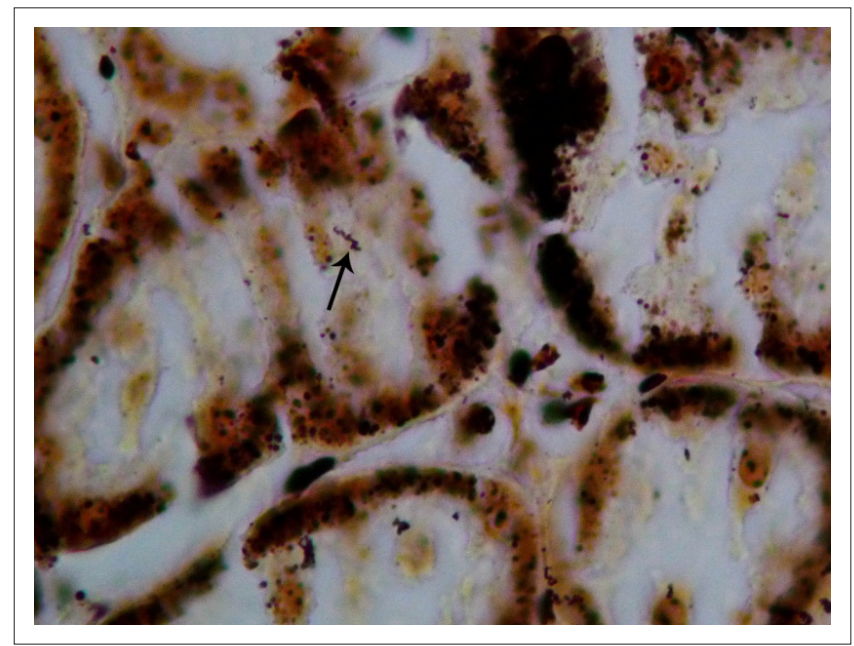

Source: Taken by optika B353 PL, Digital Pro 3, Italy

$\times 1000$

FIGURE 5: Warthin-Starry staining of kidney. Presence of spiral shaped Leptospira (arrow) in the lumen of renal tubule.

The objective of the present study was to find a simple and inexpensive method that can be performed in any laboratory and can detect Leptospira in affected cases post mortem if samples from living animals are not available. Therefore, the original specimens were taken from a slaughterhouse.

The findings of this study agreed with the results of previous studies indicating that leptospires were localised on the apical surface of epithelium and in the lumens of proximal convoluted tubules of kidneys in carrier animals (Marshall 1974; Sterling \& Thiermann 1981). Seibold, Keech and Bokelman (1961) reported the presence of leptospires in the lumen of tubules at the corticomedullary junction of carrier cattle with an extensive inflammatory cortical reaction. They suggested that leptospires migrated to the corticomedullary tubules because of damage to the cortical tubules, but in this study no Leptospira was identified in the medullary tubules.

Silver staining is not commonly used as a diagnostic method for leptospirosis. In the present study, WS staining was applied to evaluate it as a rapid, easy, available technique that can be performed on formalin-fixed tissues. Some studies have described its efficacy for detecting leptospires in animals and humans (Chappel et al. 1992; De Brito et al. 1996; Léon et al. 2006; Ortega-Pacheco et al. 2008; Sebastian et al. 2005). A few studies have reported a low frequency of positive results using this method (Chappel et al. 1992; Hunter et al. 1987). In this study, WS technique showed fewer positive results than PCR. This may be because of a low burden of Leptospira in the kidney. There are some difficulties of interpretation in this method because reticulin fibres stain with WS and leptospiral fragments are not recognisable, especially if few organisms are present (Szeredi \& Haake 2006). PCR was found in this study to be a more sensitive technique that could detect low numbers or deformed organisms in the tissue.

In this study, Leptospira was detected in the kidneys of all seropositive animals by silver staining. Similarly, WS positivity in the kidney is reported more frequently in seropositive animals in other studies. Jansen et al. (2007) investigated leptospirosis in wild boars in Germany. They found antibodies to leptospires in 25 (18\%) out of 141 wild boars. A total of 29 kidney specimens (17 from seropositive and 12 from seronegative boars) were examined with HE and WS. Moderate to severe chronic lymphoplasmacytic interstitial nephritis was observed in 15 (88\%) kidney samples from the 17 seropositive boars and five out of 12 seronegative boars. Leptospires were detected by silver staining in three (30\%) out of 10 specimens from seropositive wild boars with chronic interstitial nephritis and were confirmed by PCR targeting LipL32 in two of the Leptospira-positive samples. These researchers stated that wild boars could be a potential source of human leptospirosis in urban environments. Hodgin, Miller and Lozano (1989) easily found spirochetes in the cortical and medullary interstitium of the kidney as well as the liver and placenta of aborted foals by WS in the acute stage of disease.

In the present investigation, the histopathological and WS findings were similar to results described by Rossetti et al. (2004). They detected leptospires in the kidneys of 41 wild house mice (Mus musculus) with three diagnostic techniques, namely bacteriology, WS and IHC. Leptospira belonging to the Ballum serogroup was isolated from 16 (39\%) out of 41 samples by culture and identified in $18(44 \%)$ and $19(46 \%)$ kidney specimens by WS and IHC respectively. With WS staining, leptospires were identified in high numbers on the apical surface of epithelial cells and in the lumen of cortical tubules. IHC detected the presence of the agent in one sample that was negative with WS staining. These researchers suggested that low numbers of leptospires in that sample was the reason for WS negativity. Histopathologically, 13 out of 19 infected mice showed interstitial nephritis caused by mononuclear cell infiltration. These researchers observed that these three techniques had a high level of agreement and no significant differences between them were present. In agreement with the present study, no relationship was found between severity of lesions and presence of leptospires. 
The higher sensitivity of PCR technique as opposed to WS has been reported in previous studies. Fornazari et al. (2012) compared different techniques for diagnosing leptospirosis in kidney, liver and blood samples of 465 slaughtered sheep. The sera were analysed by MAT. Kidney and liver samples of seropositive animals were examined using four techniques, including bacterial culture, WS, conventional PCR (cPCR) and quantitative PCR (qPCR). With MAT, 21 animals (4.5\%) were positive. None were positive by bacteriological culture. WS and CPCR techniques detected four and six positive kidney samples respectively. Eleven animals were positive by qPCR (eight kidney samples and three livers). Their results showed that qPCR had the highest sensitivity amongst the techniques used to detect Leptospira spp. in tissue samples, followed by CPCR, WS and bacterial culture. However, some studies have reported high sensitivity for WS. Wild et al. (2002) examined formalin-fixed kidneys of 12 dogs with chronic interstitial nephritis for leptospirosis. Leptospira was identified in six samples with silver staining. Leptospiral antigens were detected by IHC in all WS positive samples. Sections that were negative by silver staining were also negative by immunostaining.

The association of interstitial nephritis with positive PCR results and demonstration of leptospires in the kidney specimens indicate that cows act as a maintenance host for Leptospira spp. in this area (Hernández-Rodríguez et al. 2011). The differences between two techniques may be related to lack of experience with the WS technique (Orrego et al. 2003). However, it is accepted that if silver staining is performed carefully, it is a highly sensitive and reliable method (Thiermann 1977). Further studies will be carried out to determine the bacterial burdens in various tissues, especially kidney, in different hosts. Also, localisation of Leptospira in the kidney should be investigated in the acute and chronic stages of disease to determine in which stage the bacterial burdens are greater and can be detected by the WS technique.

\section{Acknowledgements}

The authors would like to thank the Vice Chancellor of Research at the Shahid Bahonar University of Kerman for their financial support and cooperation.

\section{Competing interests}

The authors declare that they have no financial or personal relationship(s) that may have inappropriately influenced them in writing this article.

\section{Authors' contributions}

S.A. (Shahid Bahonar University of Kerman) was the project leader and designer, R.K. (Shahid Bahonar University of Kerman) was the pathologist and leader and E.R. (Shahid Bahonar University of Kerman) was responsible for some of the experiments.

\section{References}

Adler, B. \& De la Peña-Moctezuma, A., 2010, 'Leptospira and leptospirosis', Veterinary Microbiology 140, 287-296. http://dx.doi.org/10.1016/j.vetmic.2009.03.012

Ahmad, S.N., Shah, S. \& Ahmad, F.M., 2005, 'Laboratory diagnosis of leptospirosis', Journal of Postgraduate Medicine 51(3), 195-200.

Azizi, S., Tajbakhsh, E., Hajimirzaei, M.R., Gholami Varnamkhasti, M., Sadeghian, H. \& Oryan, A., 2012, "Evaluation of "white-spotted kidneys" associated with leptospirosis by polymerase chain reaction based LipL32 gene in slaughtered cows', Journal of the South African Veterinary Association 83(1), 69-74. http:// dx.doi.org/10.4102/jsava.v83i1.69

Baker, T.F., McEwen, S.A., Prescott, J.F. \& Meek, A.H., 1989, 'The prevalence of leptospirosis and its association with multifocal interstitial nephritis in swine at slaughter', Canadian Journal of Veterinary Research 53, 290-294.

Bharti, A.R., Nally, J.E., Ricaldi, J.N., Matthias, M.A., Diaz, M.M., Lovett, M.A. et al., 2003, 'Leptospirosis: A zoonotic disease of global importance', Lancet Infectious Diseases 3(12), 757-771. http://dx.doi.org/10.1016/S1473-3099(03)00830-2

Céspedes, M., Tapia, R., Balda, L., Gonzalez, D., Peralta, C. \& Condori, P., 2007 'Standardization and validation of the polymerase chain reaction for early diagnosis of human leptospirosis', Revista Peruana de Medicina Experimental y Salud Pública 24, 20-26.

Chappel, R.J., Prime, R.W., Millar, B.D., Mead, L.J., Jones, R.T. \& Adler, B., 1992, 'Comparison of diagnostic procedures for porcine leptospirosis', Veterinary Microbiology 30, 151-163. http://dx.doi.org/10.1016/0378-1135(92)90110-F

De Brito, T., Sandoval, M.P., Silva, A.G., Saad, R.C. \& Colaiacovo, W., 1996, 'Intestinal spirochetosis: First cases reported in Brazil and the use of immunohistochemistry
as an aid in histopathological diagnosis', Revista do Instituto de Medicina Tropical de São Paulo 38, 45-52. http://dx.doi.org/10.1590/\$0036-46651996000100009

Ellis, T.M., Robertson, G.M., Hustas, L. \& Kirby, M., 1983, 'Detection of Leptospira in tissue using an immunoperoxidase staining procedure', Australian Veterinary Journal 60, 364-367. http://dx.doi.org/10.1111/j.1751-0813.1983.tb02849.x

Faine, S., Adler, B., Bolin, C. \& Perolat, P., 1999, Leptospira and leptospirosis, 2nd edn., MedSci, Melbourne.

Fornazari, F., Da Silva, R.C., Richini-Pereira, V.B., Beserra, H.E., Luvizotto, M.C. \& Langoni, H., 2012, 'Comparison of conventional PCR, quantitative PCR, bacteriological culture and the Warthin Starry technique to detect Leptospira spp. in kidney and liver samples from naturally infected sheep from Brazil', Journal of Microbiological Methods 90, 321-326. http://dx.doi.org/10.1016/j.mimet.2012.06.005

Hazıroğlu, R. \& Milli, Ü.H., 2001, 'Urinary system', in R. Hazıroğlu \& Ü.H. Milli (eds.), Veterinary Pathology, vol. I., Tamer Press, Ankara.

Hernández-Rodríguez, P., Díaz, C.A., Dalmau, E.A. \& Quintero, G.M., 2011, 'A comparison between polymerase chain reaction (PCR) and traditional techniques for the diagnosis of leptospirosis in bovines', Journal of Microbiological Methods 84, 1-7. http://dx.doi.org/10.1016/j.mimet.2010.10.021

Hodgin, E.C., Miller, D.A. \& Lozano, F., 1989, 'Leptospira abortion in horses', Journal of Veterinary Diagnostic Investigation 1, 283-287. http://dx.doi. org/10.1177/104063878900100401

Hunter, P., Van der Vyver, F.H., Selmer-Olsen, A., Henton, M.M., Herr, S. \& De Lange, J.F., 1987, 'Leptospirosis as cause of "white spots" kidneys in South African pig abattoirs', Onderstepoort Journal of Veterinary Research 54, 59-62.

Jansen, A., Luge, E., Guerra, B., Wittschen, P., Gruber, A.D., Loddenkemper, C. et al., 2007, 'Leptospirosis in urban wild boars, Berlin, Germany', Emerging Infectious Diseases 13(5), 739-742. http://dx.doi.org/10.3201/eid1305.061302

Jones, R.T., Millar, B.D., Chappel, R.J. \& Adler, B., 1987, 'Macroscopic kidney lesions in slaughtered pigs are an inadequate indicator of current leptospiral infection', Australian Veterinary Journal 64, 258-259. http://dx.doi. org/10.1111/j.1751-0813.1987.tb09700.x

Léon, A., Pronost, S., Tapprest, J., Foucher, N., Blanchard, B., André-Fontaine, G. et al., 2006, 'Identification of pathogenic Leptospira strains in tissues of a premature foal by use of polymerase chain reaction analysis', Journal of Veterinary Diagnostic Investigation 18, 218-221. http://dx.doi.org/10.1177/104063870601800216

Levett, P.N., 2001, 'Leptospirosis', Clinical Microbiology Reviews 14, 296-326. http:// dx.doi.org/10.1128/CMR.14.2.296-326.2001

Lilenbaum, W., Varges, R., Brandão, F.Z., Cortez, A., De Souza, S.O., Brandão, P.E. et al., 2008 , 'Detection of Leptospira spp. in semen and vaginal fluids of goats and sheep by polymerase chain reaction', Theriogenology 69(7), 837-842. http://dx.doi. org/10.1016/j.theriogenology.2007.10.027

Luna, L.G., 1968, Manual of histologic staining methods of the Armed Forces Institute of Pathology, 3rd edn., pp. 238-240, McGraw-Hill, New York.

Marshall, R.B., 1974, 'Ultrastructural changes in renal tubules of sheep following experimental infection with Leptospira interrogans serotype pomona', Journal of Medical Microbiology 7, 505-508. http://dx.doi.org/10.1099/00222615-7-4-505

Monahan, A.M., Callanan, J.J. \& Nally, J.E., 2009, 'Host-pathogen interactions in the kidney during chronic leptospirosis', Veterinary Pathology 46(5), 792-799. http:// dx.doi.org/10.1354/vp.08-VP-0265-N-REV

Obregón, M., Fernández, C., Rodríguez, I., Balbis, Y., Martínez, B. \& Rodríguez, J., 2004, 'Latex agglutination system for the rapid diagnosis of leptospirosis in Cuba',
Revista Panamericana de Salud Pública 16, 259-265. http://dx.doi.org/10.1590/ Revista Panamericana de Salud

Orrego, A., Giraldo de León, G. \& Ríos, B., 2003, 'Leptospirosis in high risk groups of workers from fifteen piggeries and the central abattoir in Manizales, Colombia', Archivos de Medicina Veterinaria 35, 205-213. 
Ortega-Pacheco, A., Colin-Flores, R.F., Gutiérrez-Blanco, E. \& Jiménez-Coello, M. 2008, 'Frequency and type of renal lesions in dogs naturally infected with Leptospira species', Annals of the New York Academy of Sciences 1149, 270-274. http://dx.doi.org/10.1196/annals.1428.088

Rahim, H., Gorbanpour, M. \& Haidari, M., 2005, 'Comparison of leptospiral infection in the horse and donkey', Bulletin of the Veterinary Institute in Pulawy 49, 175-178.

Rossetti, C.A., Vanasco, B.N., Pini, N. \& Carfagnini, J.C., 2004, 'Comparison of three diagnostic techniques for the detection of leptospires in the kidneys of wild house mice (Mus musculus)', Revista Pesquisa Veterinária Brasileira 24(1), 6-10.

Scanziani, E., Sironi, G. \& Mandelli, G., 1989, 'Immunoperoxidase studies on leptospiral nephritis of swine', Veterinary Pathology 26, 442-444.

Sebastian, M., Giles, R., Roberts, J., Poonacha, K., Harrison, L., Donahue, J. et al., 2005 'Funisitis associated with leptospiral abortion in an equine placenta', Veterinary Pathology 42, 659-662. http://dx.doi.org/10.1354/vp.42-5-659

Seibold, H.R., Keech, H. \& Bokelman, D.L., 1961, 'Histopathologic and serologic study of subclinical leptospirosis among cattle', Journal of the American Veterinary Medical Association 138, 424-430.

Sterling, C.R. \& Thiermann, A.B., 1981, 'Urban rats as chronic carriers of leptospirosis: An ultrastructural investigation', Veterinary Pathology 18, 628-637.
Szeredi, L. \& Haake, D.A., 2006, 'Immunohistochemical identification and pathologic findings in natural cases of equine abortion caused by leptospiral infection Veterinary Pathology 43(5), 755-761. http://dx.doi.org/10.1354/vp.43-5-755

Tansuphasiri, U., Chanthadee, R., Phulsuksombati, D. \& Sangjun, N., 2006 'Development of a duplex-polymerase chain reaction for rapid detection of pathogenic Leptospira', Southeast Asian Journal of Tropical Medicine and Public Health 37, 297-308.

Thiermann, A.B., 1977, 'Incidence of leptospirosis in the Detroit rat population', American Journal of Tropical Medicine and Hygiene 26, 970-974.

Thrusfield, M., 2005, Veterinary epidemiology, 3rd edn., Blackwell, Ames.

Vital-Brazil, J.M., Balassiano, I.T., De Oliveira, F.S., De Souza Costa, A.D., Hillen, L. \& Pereira, M.M., 2010, 'Multiplex PCR-based detection of Leptospira in environmental water samples obtained from a slum settlement', Memórias 02762010000300020

Wild, C.J., Greenlee, J.J., Bolin, C.A., Barnett, J.K., Haake, D.A. \& Cheville, N.F., 2002 'An improved immunohistochemical diagnostic technique for canine leptospirosis using antileptospiral antibodies on renal tissue', Journal of Veterinary Diagnostic Investigation 14, 20-24. http://dx.doi.org/10.1177/104063870201400105

Yang, C.W., Wu, M.S. \& Pan, M.J., 2001, 'Leptospirosis renal disease', Nephrology Dialysis Transplantation 16, 73-77. http://dx.doi.org/10.1093/ndt/16.suppl_5.73 